\title{
A BRIEF OVERVIEW IN THE STUDY OF ARCHAEOLOGICAL MATERIALS THROUGH THE TECHNIQUE OF X-RAY DIFFRACTION (XRD)
}

\author{
Abreu, C. M.*; Souza, D. N.; Paschoal, C. M. M. \\ Physics Department, Federal University of Sergipe, São Cristóvão, Sergipe, Brazil
}

*carolabreu.fisica@gmail.com

\begin{abstract}
X-Ray Diffraction is a technique widely used in archaeometry studies to investigate the chemical composition of pigments, ceramics, lithics artifacts, bones, shells and others. It is a destructive technique which make possible the identification and quantification of different crystalline phases based on the diffraction pattern analysis in the powder samples. The analysis of archaeological materials provides information to the physics and archaeologists about the technology and the materials used in antiquity. The analytical studies can be used to evidence the differences in the cultural evolution at different geographical regions that occurred during the time. The aim of this work is to report a review the studies of characterization of archaeological materials using X-Ray Diffraction (XRD). In this work, will also be presented preliminary results using XRD for characterizing archaeological shells from the archaeological site of Sergipe - Alagoas, Brazil
\end{abstract}

